\title{
PELATIHAN OPTIMASI DESAIN GROUNDBED PADA SISTEM SACP UNTUK PIPA BAJA DI TANAH KAWASAN ITS SEBAGAI PENINGKATAN KOMPETENSI GURU DAN SISWA SEKOLAH ALAM INSAN MULIA SURABAYA
}

\author{
Oleh: \\ Tubagus N. Rohmannudin ${ }^{1}$, Sulistijono², M. Rizal Pambudi ${ }^{3}$ \\ 1,2,Institut Teknologi Sepuluh November \\ 1roma_r2001@yahoo.com
}

\begin{abstract}
Abstrak
Groundbed adalah anoda yang dibungkus dengan backfill sebagai salah satu variabel di dalam sistem proteksi katodik di dalam tanah. Salah satu hal yang harus diperhatikan dalam teknologi groundbed adalah komposisi penyusun backfill. Backfill berfungsi sebagai penjaga permukaan anoda supaya selalu tetap basah. Hal ini ditujukan untuk memudahkan aliran arus proteksi dari anoda ke katoda melalui media tanah. Selain itu, dimensi dan perbandingan berat antara anoda dan backfill di dalam groundbed juga mempengaruhi kinerja dari grounbed. Kenyataan di lapangan seringkali terjadi kesulitan dalam pembuatan dan instalasi groundbed sehingga banyak dijumpai kesalahan-kesalahan yang mengakibatkan groundbed tidak bekerja secara maksimal. Oleh sebab itu optimasi pembuatan grounbed dirancang untuk meningkatkan kemampuan dan kompetensi dalam teknologi groundbed. Sekolah Alam Insan Mulia merupakan salah satu SMA di Surabaya yang dijadikan objek pengembangan desain grounbed. Hal ini ditunjukkan dengan antusiasnya para guru dan Siswa Sekolah Alam Insan Mulia (SAIM) ketika tim pengabdian masyarakat menawarkan program pelatihan ini. Oleh sebab itu Teknik Material dan Metalurgi FTI-ITS sebagai Institusi Perguruan Tinggi tergerak untuk melakukan kegiatan pengabdian masyarakat dengan melaksanakan Pelatihan Teknologi Groundbed pada Sistem SACP (Sacrifacial Anode Cathodic Protection) sebagai Peningkatan Kompetensi Sekolah Menengah Tingkat Atas/ Kejuruan/ Sederajat. Pelatihan ini diadakan di Teknik Material dan Metalurgi FTI-ITS. Metode Pelatihan yang digunakan adalah presentasi materi oleh Tim Pengabdi yang dilanjutkan dengan eksperimen di Laboratorium. Hasil pelatihan ini menunjukkan adanya peningkatan wawasan dan pemahanan Guru dan Siswa SAIM yang dapat dilihat dari hasil uji tulis di akhir program.
\end{abstract}

Kata Kunci: groundbed, SACP, katoda, anoda

\begin{abstract}
Groundbed is anode that wrapped by backfill as one veriable in the cathodic protection in the ground. One of the things that must be considered in groundbed technology is the composition of the constituent backfill. The function of Backfill is keeper the anode surface serves as a guard in order to always stay wet. It is intended to facilitate the protection current flow from the anode to the cathode through the soil media. Additionally, the dimensions and the weight ratio between the anode and the backfill in groundbed also affect the performance of grounbed. Reality on the ground is often occur difficulties in the manufacture and installation groundbed so many common mistakes that lead to groundbed do not work optimally. Therefore, optimization of the manufacturing grounbed designed to enhance skills and competencies in technology groundbed. Sekolah Alam Insan Mulia (SAIM) is one high school in Surabaya, as object design development grounbed. This is demonstrated by the enthusiasm of the teachers and students of Sekolah Alam Insan Mulia as a community service team offers this training program. Therefore, Materials and Metallurgical Engineering FTI-ITS as a Higher Education Institution moved to do community service activities by implementing Groundbed Technology Training System on SACP (Sacrifacial Anode Cathodic Protection) As Competency Enhancement Upper Level High School / Vocational / equivalent. Training Method of this program are the presentation and experiment in Laboratory by Team Pengabdi. The results of this training show an increase in insight and defense of teachers and Students of SAIM wich can be seen from the results of the written test at the end of the program.
\end{abstract}

Keywords: groundbed, SACP, katode, anode 


\section{PENDAHULUAN}

Korosi atau karat merupakan suatu kondisi degradasi logam yang diakibatkan oleh reaksi reduksi-oksidasi yang terjadi pada logam dengan berbagai zat yang ada di lingkungan sekitarnya sehingga menghasilkan suatu senyawa yang tidak dikehendaki. Contoh korosi yang umum terjadi adalah perkaratan logam besi. Korosi tidak dapat dicegah maupun dihentikan secara total tapi korosi ini hanya bisa diperlambat lajunya sehingga memperlambat pula proses perusakan yang terjadi pada material tersebut. Melihat keadaan yang tidak menguntungkan seperti ini dimana korosi merupakan proses alam yang tidak dapat dihindari namun hanya dapat diminimalisir atau dicegah maka korosi tentu sangat merugikan karena dapat mengurangi kemampuan suatu material atau logam dalam menerima suatu beban.

Dalam dunia industri eksplorasi minyak dan gas bumi, fenomena korosi sering dijumpai pada pipa-pipa baja (pipeline). Pipa baja biasa digunakan untuk memindahkan zat hasil pemrosesan seperti cairan, gas, uap, zat padat yang dicairkan maupun serbuk halus. Material yang digunakan sebagai pipa sangat banyak diantaranya adalah beton cor, gelas, timbal, kuningan (brass), tembaga, plastik, aluminium, besi tuang, namun pada umumnya material yang umum digunakan sebagai pipa adalah baja karbon dan baja paduan. Pada pipa baja yang ditanam didalam tanah sangat rawan terjadi korosi akibat pengaruh lingkungan sekitarnya. Proteksi pada pipa baja diperlukan agar menghambat laju korosi sehingga pipa tersebut tidak mengalami kegagalan atau kerusakan yang dapat membahayakan lingkungan sekitar. Proteksi pada pipa saat ini sudah mengalami beberapa kemajuan, proteksi yang biasa digunakan antara lain dengan menggunakan metoda proteksi katodik, inhibitor, dan penggunan lapisan pelindung (coating). Masing masing metoda memiliki keunggulan dan kekurangan tersendiri.

Proteksi katodik adalah perlindungan logam dari korosi dengan menempatkan logam yang dilindungi sebagai katoda dan logam yang dikorbankan sebagai anoda. Pada proteksi katodik di dalam tanah, anoda harus di lengkapi dengan backfill. Perpaduan anoda dan backfill ini disebut sebagai groundbed. Backfill terdiri dari gypsum, bentonit dan clay yang berfungsi untuk menjaga permukaan anoda supaya tetap basah. Hal ini untuk memudahkan aliran arus proteksi dari anoda ke katoda melalui media tanah. Dalam kenyataan di lapangan seringkali ditemui adanya groundbed yang kurang bekerja dengan baik sehingga mempengaruhi proses perlindungan terhadap struktur logam. Fenomena ini bisa disebabkan oleh beberapa hal diantaranya, dimensi atau ukuran groundbed yang kurang sesuai, persentase komposisi backfill yang tidak tepat untuk jenis tanah, dll. Oleh sebab itu perlu diadakan sebuah pelatihan mengenai teknologi groundbed pada sistem SACP (Sacrifacial Anode Cathodic Protection).

Berdasarkan penjelasan tersebut, maka dipelukan adanya transfer ilmu dan teknologi tentang teknologi groundbed sistem SACP dari Perguruan Tinggi ke Institusi Pendidikan Tingkat Atas/ Kejuruan/ Sederajat sebagai peningkatan kompetensi untuk pembekalan di dunia kerja. Salah satu Intitusi Pendidikan tersebut adalah Sekolah Alam Insan Mulia (SAIM). Hal ini dibuktikan dengan antusiasnya para guru dan siswa Sekolah Alam Insan Mulia untuk mengikuti program ini ketika diadakan promosi oleh Tim Pengabdian dari Jurusan Teknik Material dan Metalurgi FTI-ITS. Oleh karena itu, Jurusan Teknik Material dan Metalurgi FTI-ITS sebagai Institusi Perguruan Tinggi tergerak untuk melakukan kegiatan pengabdian masyarakat dengan melaksanakan Pelatihan Teknologi Groundbed pada Sistem SACP (Sacrifacial Anode Cathodic Protection) sebagai Peningkatan Kompetensi Guru dan Siswa Sekolah Menengah Tingkat Atas/ Kejuruan/ Sederajat.

\section{METODE PELAKSANAAN}

Program Pengabdian Masyarakat ini memberikan pelatihan mengenai teknologi praktis mengenai teknologi groundbed terhadap Guru dan Siswa Sekolah Alam Insan Mulia.

\section{Strategi}

Program Pengabdian Masyarakat ini memiliki beberapa strategi agar program ini dapat memberikan manfaat yang tinggi, antara lain:

1. Tim melakukan studi lapangan ke Sekolah Alam Insan Mulia.

2. Tim mengumpulkan informasi mengenai kondisi Sekolah Alam Insan Mulia.

3. Tim memberikan penyuluhan tentang manfaat dan penggunaan teknologi groundbed ke Sekolah Alam Insan Mulia. 
4. Tim mempromosikan kegiatan pelatihan ke Sekolah Alam Insan Mulia.

5. Tim memfasilitasi program pelatihan teknologi groundbed yang diadakan di Jurusan Teknik Material dan Metalurgi FTI-ITS.

6. Tim melakukan monittoring dan evaluasi program pelatihan.

7. Tim membuat perencanaan program berkelanjutan.

\section{Rencana Kegiatan}

Rencana Kegiatan Program ini dilakukan secara bertahap. Kegiatan dimulai dengan penyiapan kegiatan melalui komunikasi awal internal terhadap tim Jurusan Teknik Material dan Metalurgi FTI-ITS. Kegiatan ini dilakukan untuk menyiapkan kondisi internal tim terhadap penyelenggaraan kegiatan program pengabdian masyarakat. Kegiatan ini juga melakukan penyiapan terhadap keperluan peralatan, bahan, personil dan jadwal kegiatan. Kegiatan selanjutnya melakukan komunikasi awal terhadap pihak sekolah Sekolah Alam Insan Mulia. Kegiatan ini melakukan perkenalan terhadap para guru dan perwakilan siswa. Kegiatan ini juga melakukan studi mengenai pemahaman dan penguasaan teknologi teknologi groundbed di lingkungan SMA. Kegiatan ini diharapkan mendapatkan masukan mengenai kebutuhan materi dan pengetahuan praktis dari para guru dan siswa SMA. Tim ITS juga akan membuka koordinasi dan masukan dari pihak industri dan praktisi yang bergerak di teknologi groundbed. Kegiatan selanjutnya melakukan koordinasi internal tim ITS untuk penyiapan dan penyempurnaan peralatan dan bahan yang telah disesuaikan dan disempurnakan berdasarkan masukan dari kajian awal. Penyiapan peralatan meliputi penyiapan katoda, anoda, bakcfill, kabel dll sebagai bahan penelitian, persiapan lokasi pipa pengujian, peralatan mekanik, peralatan listrik, ruangan dan bahan pelatihan. Penyiapan bahan meliputi penyiapan rectifieravometer, elektrode referensi, standarisasi pengujian, pembuatan materi pelatihan, sistem monitoring, sistem evaluasi dan sistem monitoring untuk keberlanjutan program. Kegiatan dilanjutkan dengan pelaksanaan pelatihan terhadap masyarakat Sekolah Alam Insan Mulia dan monitoring terhadap keberlanjutan program.

\section{Keberlanjutan Program}

Kegiatan program pengabdian masyarakat dilanjutkan dengan sistem monitoring terhadap keberlanjutan penguasaan materi dan aplikasi teknologi teknologi groundbed di kalangan Sekolah Alam Insan Mulia. Keberlanjutan program ditunjukkan dengan peningkatan pemahaman dan penguasaan teknologi groundbed oleh Sekolah Alam Insan Mulia.

Sekolah Alam Insan Mulia diharapkan dapat melanjutkan pengembangan teknologi teknologi groundbed di lingkungannya.

Dengan program ini, diharapkan dapat meningkatkan pemberdayaan Sekolah Alam Insan Mulia dan mendukung kegiatan industri belajar mengajar yang ada disana. Kegiatan ini diharapkan dapat meningkatkan kualitas dan daya saing Sekolah Alam Insan Mulia.

\section{HASIL DAN PEMBAHASAN}

Secara umum groundbed dirancang mempunyai tahanan sebesar 1 ohm atau lebih rendah daripada itu. Beberapa factor yang mempengaruhi nilai resistance sebuah groundbed adalah soil resistivity, panjang area aktif, Kualitas coke dan konsumsi anoda. Groundbed resistance sering berubah dari waktu kewaktu. Groundbed Current Output (Keluaran arus groundbed) keluaran arus groundbed merupakan fungsi dari DC power system sebagai sumber voltage dan tahanan sirkuit (berdasarkan ohm law $\mathrm{V}=\mathrm{I} \mathrm{x}$ $R)$. Dengan berjalannya waktu maka tahanan groundbed naik sehingga membuat keluaran arus menurun. Disaat inilah Voltage output bisa diatur sesuai kebutuhan. Umur Desain, groundbed mempunyai umur desain dan umur actual operasi. Umur desain dihitung berdasarkan jumlah anoda yang digunakan serta laju konsumsi untuk mendapatkan keluaran arus yang diinginkan. Umur actual operasi bisa melebihi umur desain atau pada beberapa kasus kurang dari umur desain dikarenakan kesalahan desain, kerusakan instrument saat instalasi dan pengoperasian groundbed yang melebihi kemampuan desainnya.

Deep well groundbed mempunyai 2 zona, yaitu zona aktif dan zona pasif. Zona aktif adalah zona yang dimulai dari bawah lubang hingga permukaan kolom coke breeze. Zona pasif berada diatas zona aktif sampai dengan permukaan tanah dengan jarak bervariasi tergantung kedalaman groundbed. Zona pasif ini diperlukan untuk memastikan bahwa jarak groundbed sudah mencapai zona remote atau terbebas dari efek gradient sehingga jangkauan proteksi bisa jauh.

Zona aktif adalah tempat anode berada. Ada beberapa pertimbangan praktis dalam 
menentukan panjang zona aktif dimana akan mempunyai pengaruh yang sangat besar terhadap resistance groundbed. Persamaan Dwight digunakan untuk melakukan pendekatan terhadap resistance groundbed. Dalam persamaan tersebut ada 2 faktor yang sangat berpengaruh yaitu panjang area aktif dan soil resistivity, sedangkan diameter lubang tidak berpengaruh secara signifikan. Hal-hal tersebut diberikan selama pelatihan.

Pelatihan groundbed ini sebagai pemberdayaan pelajar Sekolah Alam Insan Mulia Surabaya dilaksanakan di Jurusan Teknik Material dan Metalurgi FTI-ITS Surabaya. Pengetahuan yang diberikan berupa teknologi grounbed proteksi katodik mulai dari teori, pembuatan, sampai dengan instalasi atau pemasangan.

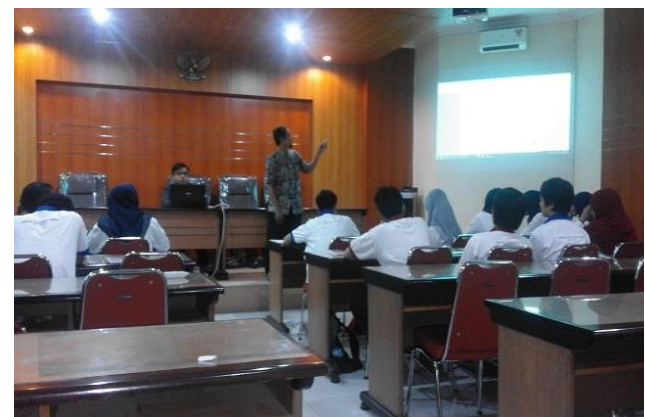

Gambar 1. Pelatihan grounbed

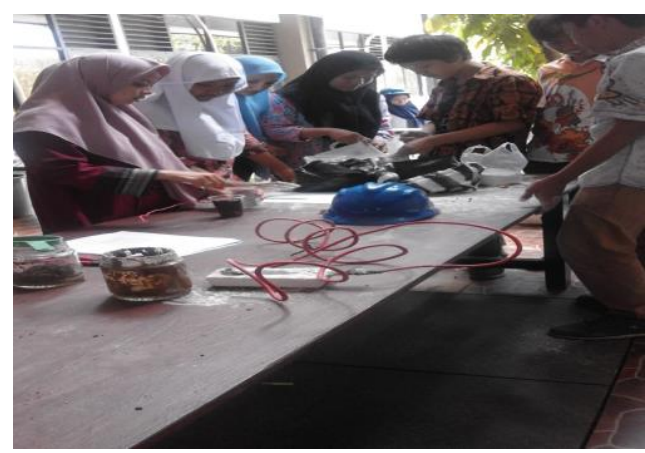

Gambar 2. Praktikum groundbed

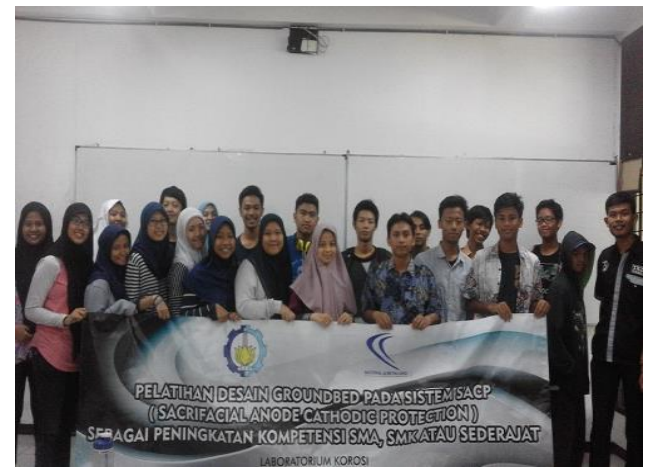

Gambar 3. Penutupan pelatihan groundbed
Pelatihan ini bertujuan untuk memberikan ilmu pengetahuan konsep dasar teknologi groundbed untuk meningkatkan pemahaman dan kompetensi Sekolah Alam Insan Mulia. Acara tersebut dibuat dalam bentuk pelatihan atau kegiatan workshop teknologi groundbed kepada Sekolah Alam Insan Mulia. Manfaat dari kegitan tersebut adalah peningkatan pemahaman dan kompetensi dalam teknologi groundbed kepada Sekolah Alam Insan Mulia. Peningkatan kompetensi ini sangat membantu para guru untuk meningkatkan mutu pembelajaran khususnya yang berhubungan dengan tekbologi groundbed. Sedangkan bagi para siswa, dapat dijadikan bekal ilmu pengetahuan dan perencanaan pembelajaran selama masa sekolah maupun setelah lulus dari sekolah. Pelatihan ini juga menjadi capaian Jurusan Teknik Material dan Metalurgi dalam melaksanakan salah satu Tri Dharma Perguruan Tinggi yaitu Pengabdian kepada Masyarakat.

\section{SIMPULAN DAN SARAN}

Pelatihan grounbed untuk para Guru dan Siswa SAIM telah dilakukan sebagai bentuk pelaksanaan salah satu Tri Dharma Perguruan Tinggi yaitu Pengabdian kepada Masyarakat. Pelatihan ini dilakukan di Jurusan Tenik Material Metalurgi ITS. Peserta pelatihan mendapatkan pengetahuan dan kemampuan mengenai teknologi groundbed. Peserta pelatihan menyatakan bahwa pelatihan ini sangat berguna dan bermanfaat bagi bekal ilmu untuk kedepannya.

Saran untuk peningkatan kualitas dari program ini adalah dengan melakukan kunjungan ke Industri Groundbed. Kunjungan ke Industri ini diharapkan dapat semakin meningkatkan pemahaman akan teknologi Groundbed dan juga membuka peluang kerjasama.

\section{DAFTAR PUSTAKA}

A. W. Peabody. 2001. Control of Pipeline Corrosion. Edited by Ronald L Bianchetti. Texas: NACE International the Corrosion Society.

Aditya dkk, 2012. Pengaruh Lebar Goresan Pada Lapis Lindung Polietilena dan pH Tanah Terhadap Proteksi Katodik Anoda Tumbal Pada Baja AISI 1045 di Lingkungan Tanah Rawa. Jurnal POMITS. 
ASM International, ASM Metal Handbook Vol 13A Corrosion: Fundamental, Testing, and Protection, 2003. Novelty, $\mathrm{OH}$

Callister, William. D. Jr,. 2001. Fundamentals of Materials Science and Engineering. Fifth Edition. USA: John Wiley \& Sons. Inc.

Chevron USA. 2008. Cathodic Protection for Pipelines. USA: Chevron USA.Inc.

Fontana, Mars G. 1986. Corrosion Engineering. Singapore: McGraw-Hill International.

Gurrappa, I., 2005. "Cathodic protection of cooling water systems and selection of appropriate materials". Journal of Materials Processing Technology 166 (2005): 256-267.

Kusumo, Eko. 2013. Studi Pengaruh Scratch Permukaan terhadap Laju Korosi pada Pelat Baja Karbon Rendah. Surabaya: ITS.

Mars, G. Fontana. 1987. Corrosion Engineering, 3rd edition. New York: Mc Graw-Hill Book Company.

Miftahul dkk. 2012. Pemetaan Resistivitas Tanah Untuk Memprediksikan
Kerusakan Konstruksi. Jurnal POMITS.

NACE Standard RP0169-2002, Control Of External Corrosion Of Underground or Submerged Metallic Piping System, Houston, TX : NACE.

Nurus dkk. 2013. Pengaruh Goresan Lapis Lindung dan Salinitas Air Laut Terhadap Arus Proteksi Sistem Impressed Current Cathodic Protection (ICCP) Pada Pipa Api $5 \mathrm{~L}$ Grade B. Jurnal POMITS.

Parker, Marshall, E,. Edward, G, Peattie,. 1999. Pipeline Corrosion and Cathodic Protection. Third Edition. USA: Elsevier Science.

Rizky Ayu, Hasan Ikhwani, Heri Supomo. Analisa Desain Sistem Impressed Current Cathodic Protection (ICCP) pada Offshore Pipeline Milik JOB Pertamina-Petrochina East Java.

Roberge, Pierre, R,. 2000. Handbook of Corrosion Engineering. USA: The Mc.Graw-Hill Companies Inc.

Sulistijono, 2000. Korosi Material dan Pengendalian. Surabaya: ITS 